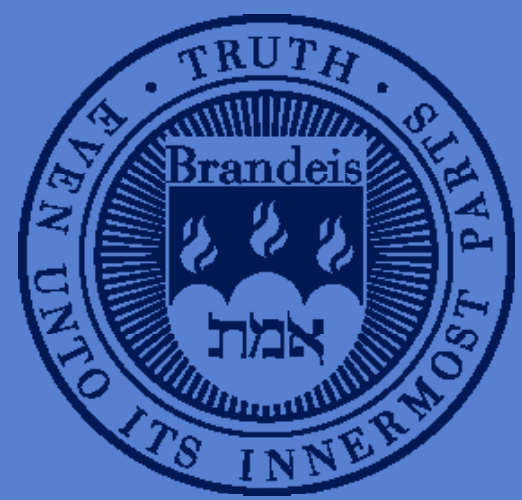

\title{
Proprietary Data, Competition, and Consumer Effort: An Application to Telematics in Auto Insurance
}

Imke Reimers, Economics Department, Northeastern University

Benjamin R. Shiller, Economics Department, Brandeis University

Working Paper Series 


\title{
PROPRIETARY DATA, COMPETITION, AND CONSUMER EFFORT: AN APPLICATION TO TELEMATICS IN AUTO INSURANCE*
}

\author{
Imke Reimers \\ Northeastern University
}

Benjamin R. Shiller

Brandeis University

Jan 8, 2018

\begin{abstract}
:
Firms are increasingly able to monitor and collect proprietary data on their customers' behaviors, raising concerns among antitrust authorities that incumbents may use such data to soften competition. Focusing on auto insurance monitoring programs which offer tailored discounts to consumers driving safely, we examine the impact of proprietary data collection on incumbent profits. We find that incumbents' profits initially increase but are eroded by competition from other firms offering similar programs. We further find that these monitoring programs reduce fatal accidents. Yet the benefits are short-lived. Incumbents, who do not necessarily internalize the full costs of accidents, typically monitor their customers only temporarily. Thus, regulation incentivizing permanent monitoring may improve welfare by reducing moral hazard.
\end{abstract}

Keywords: Proprietary data, competition, asymmetric information, switching costs, car insurance, privacy (JEL: D43, D82, L13, L40)

\footnotetext{
${ }^{*}$ We thank James Dana, Carol Osler, and Joel Waldfogel for helpful suggestions. We would also like to thank Shane Greenstein, Gerard McCullough, and Robert Shiller for useful feedback. We appreciate comments from seminars and conferences at Brandeis University, Georgia State, Harvard Business School, Mannheim University, Northeastern University, and the University of Zurich. We are grateful to Aaron Brandenburg at the National Association of Insurance Commissioners for providing state-level insurer revenue and cost data, as well as representatives at Progressive, AllState and The Hartford for generously providing data on industry profits and program entry dates. We greatly benefited from research assistance by Sean Hickey and Sisi Xie.
} 


\section{Introduction}

Obtaining consumer information might allow a firm to earn supernormal profits by identifying and targeting profitable consumers. But if competitors can collect similar information, incumbents may not have a lasting competitive advantage unless previously gathered proprietary information is marginally useful for segmenting consumers. Whether proprietary data conveys a lasting advantage is therefore an empirical question, one which has attracted considerable attention among

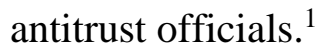

Access to more information about consumer behavior might impact markets beyond profits, for example by mitigating moral hazard problems or reducing adverse selection in insurance markets. An omniscient insurer charging individualized prices reflecting future costs may improve efficiency, but may yield insurance unaffordable for some. In the extreme, if each consumer faces a price that perfectly reflects their ex-post realized costs, insurance ceases to function as insurance, and consumers can no longer mitigate against risks. These concerns should be weighed against the potential benefits of reducing moral hazard problems.

In this paper, we analyze the impact of consumer monitoring on firm profits and consumer behavior. We first investigate whether the commonly assumed relationship between the number of firms and market competitiveness continues to hold when incumbents monitor their consumers. Second, we examine whether available monitoring technology can solve potential moral hazard problems. In doing so, we extend a large recent literature which has focused on the impacts of monitoring firms, rather than monitoring consumers (see Dranove and Jin's 2010 review article).

\footnotetext{
${ }^{1}$ See, for example, https://www.wsj.com/articles/eu-competition-chief-tracks-how-companies-use-big-data1514889000, and https://www.ftc.gov/public-statements/2016/09/deconstructing-antitrust-implicationsbig-data
} 
We focus on a salient example of consumer monitoring: Pay How You Drive (PHYD) auto insurance. PHYD programs employ telematics devices which collect proprietary data on risky behaviors such as hard braking, speeding, and late-night driving when installed in an insured's car. Tailored discounts are then offered to safe drivers. ${ }^{2}$ PHYD auto insurance is just one of many examples of the internet-connected data collection devices, i.e. the internet of things, used by firms to monitor consumers. Health and life insurers have begun using wearables (e.g. Apple watches or Fitbits) to monitor enrollees, offering discounts for meeting specific fitness goals. ${ }^{3}$ Some property insurers now also offer telematics devices. ${ }^{4}$ Monitoring may increase in non-insurance contexts as well. For example, casinos now monitor customers, giving additional benefits and services only to profitable consumers. ${ }^{5}$

Our empirical analysis is motivated by intuition from a simple theoretical model. A key insight from the model is that data collected in the past may be useful for segmenting inherently good from inherently bad drivers, but past data are of no use for mitigating the moral hazard problem. Hence if moral hazard is the primary asymmetric information problem, then monitoring may allow a monopolist to increase profits, whereas the collected data offer no lasting competitive advantage for an incumbent. But if adverse selection is relatively important, then the incumbent can utilize previously collected data to segment consumers. Entrants, by contrast, would have to collect such data from scratch to segment consumers. If collecting data is somehow costly, either because consumers dislike being monitored or data collection has explicit costs, then the incumbent may

\footnotetext{
2 PHYD insurance differs from traditional forms of targeted pricing (Dubé and Misra, 2017; Rossi et al., 1995, 1996; Shiller, 2016; Waldfogel, 2015) which condition prices on perceived willingness to pay. PHYD prices instead reflect differences across individuals in expected accident cost.

${ }^{3}$ https://www.wsj.com/articles/employees-get-apple-watch-for-25-but-theres-a-catch-1457039127

${ }^{4}$ http://www.getroost.com/partners

${ }^{5}$ https://www.wsj.com/articles/in-las-vegas-drinks-flow-a-little-less-freely-1492536818
} 
maintain a competitive advantage even after competing firms introduce similar programs. ${ }^{6}$ Whether PHYD insurance programs impact competition is thus an empirical question.

In our empirical analysis, we exploit variation in the entry timing of PHYD insurance across states and insurers, arising from differences in regulations across states and differences in the initial introduction date of PHYD across insurers. Using a difference-in-difference estimation strategy, we relate profits and fatal accidents to the number of PHYD insurance programs introduced in a state.

We find the first firm to offer PHYD insurance in a state increases profits, whereas later entrants do not significantly gain from introducing PHYD insurance. We also find that the presence of four or five firms in a market significantly reduces the incumbent's supernormal rents, but time alone does not erode profits. Our estimates are consistent with the prevailing wisdom that three or four firms are sufficient to restore competition (Bresnahan and Reiss, 1991), supporting the four-firm concentration ratio historically used by regulators. ${ }^{7}$ We thus find no evidence that previously gathered data on consumer behavior provide a lasting competitive advantage. We furthermore confirm that exogenous forces drive PHYD insurance entry.

We then examine whether PHYD programs have a measurable impact on driving behavior, using information on car accidents and fatalities in each state and year from the Fatality Analysis Reporting System (FARS). Fatal accidents provide an auspicious context because many of the monitored driving behaviors relate to chances of being in the most serious kinds of accidents. We find evidence suggesting that drivers become safer: the number of fatalities per registered vehicle

\footnotetext{
${ }^{6}$ See Klemperer $(1987,1995)$ for and overview of switching costs.

${ }^{7}$ Before 1982, the four-firm concentration ratio was used to measure market concentration.

https://www.justice.gov/atr/2010-us-horizontal-merger-guidelines-historical-and-international-perspective
} 
decreases significantly, by $1.6 \%$ for each additional firm offering PHYD insurance programs, implying enrollees reduce their fatal accident risk by approximately 50\%. Our results are in line with Weisburd (2015) and Schneider (2010), who use pseudo-exogenous variation in the financial cost of being in an accident to show consumers substantially lower accident risk when incentivized. Weisburd (2015), for example, finds drivers reduce accident risk by $25 \%$ when their expected financial burden in the event of an accident rises by $\$ 235$.

However, the benefits from monitoring may be short-lived in our context, because incumbent PHYD insurers typically monitored driving habits only for short periods (and offered prolonged discounts based on observed behavior). Consistent with this contention, we find a reduction in accident risk is strongest in the first few years in which a firm offers PHYD insurance in a state, suggesting that monitoring programs incentivize costly effort, rather than developing lasting safe driving habits. Since accidents often involve more than one party, and neither the driver nor their insurer fully internalizes others' costs, there is an argument for policy interventions that incentivize permanent monitoring. ${ }^{8}$

Our results are consistent with both adverse selection and moral hazard problems existing in the market, suggesting that increased transparency can indeed lead to better market outcomes (see Klein et al., 2016). The short-lived nature of a decline in accidents from temporary monitoring programs is consistent with moral hazard. The fact that an incumbent who chooses to monitor for short periods continues to profit later as long as no competitors enter suggests past data address an adverse selection problem. However, competition erodes profits, suggesting that while previously

\footnotetext{
8 Pain, suffering, and lost wages suffered by others in accidents may not be fully paid for. In addition, in "nofault" accident states, insurers compensate their own policy holders for costs of minor injuries, even when another driver is deemed at fault. http://www.iii.org/issue-update/no-fault-auto-insurance
} 
gathered data are effective for segmenting consumers, such data do not convey a lasting competitive advantage because competitors can duplicate them at relatively low cost.

The remainder of the paper is organized as follows. Section 2 provides an overview of the auto insurance industry and the emergence of PHYD insurance programs. Section 3 presents a simple theoretical model which motivates the subsequent empirical analyses. Section 4 describes the data. Section 5 explores the empirical relationships between PHYD insurance entry, a firm's rents, and competition. Section 6 investigates whether PHYD insurance programs impacted accident rates. A concluding section discusses policy implications.

\section{Background}

\subsection{Data Use in Auto Insurance Markets}

Auto insurance is a data intensive industry. Like in other industries, firms compete on price. But, because the expected insurance losses vary across consumers, insurers try to tailor prices to reflect predicted accident risk. In the 1990s, insurers expanded beyond using demographics and driving records to set prices, incorporating consumer characteristics such as education levels, GPAs, and credit scores (Scism, 2016). But competing firms could reverse engineer competitors' risk models and apply them to switching customers because the variables used to set prices typically must be reported in publicly available filings to the state, and those data were available for purchase..$^{9}$ In addition, information on these consumer characteristics was easily verifiable. Thus, incumbents were neither at an inherent nor permanent advantage.

\footnotetext{
${ }^{9}$ Rate filings are available for some states at: http://www.serff.com/. Other states provide rate filings upon request.
} 
This may have changed with the inception of pay how you drive (PHYD) insurance. In the early 2000s, Progressive began experimenting with telematics devices, which, when plugged into the insured's car, can directly monitor risky driving behavior, such as speeding, hard braking, quick accelerations, and night driving. Initially, the telematics devices were cumbersome and mobile networks were too expensive to transmit the requisite data on a wide scale (Scism, 2016). As data transmission became less expensive, telematics devices were increasingly used to collect data, and discounts were consequently awarded for safe driving. ${ }^{10}$ Progressive typically monitored consumers for only relatively short amounts of time, about 30 days, whereas later entrants opted for longer monitoring periods. ${ }^{11}$ The incumbent (typically Progressive) could use previously gathered data to segment its consumers, whereas new entrants and switching consumers would need to bear the costs of monitoring. Thus, incumbents might maintain a lasting competitive advantage. ${ }^{12}$

Progressive launched their full-fledged PHYD insurance program, called SnapShot, in 6 states in 2008, including Alabama, Kentucky, Louisiana, Maryland, Missouri, and New Jersey. Although Progressive expanded the program quickly, to 43 states by 2012, they might have expanded even faster in the absence of state regulations. States differ in the extent to which insurance prices are regulated. Hunter (2008) found, for example, that 15 states required that insurers obtain explicit

\footnotetext{
${ }^{10}$ Consumers can receive the full discounts from the PHYD insurance program after policy renewal, approximately 6 months, at Progressive, State Farm, and The Hartford. Liberty mutual offers full discounts after 90 days. AllState offers rewards for safe driving, which apply immediately. See the FAQ for each PHYD insurance program. Accessed Dec 27, 2016.

${ }^{11}$ Progressive, the first firm to introduce PHYD insurance in most states, monitored for 30 days, and applied discounts in the future as long as nothing else changed. State Farm employed permanent monitoring for cars with embedded telematics devices (e.g. OnStar, SYNC). Allstate constantly monitored all enrolled consumers. See Karapiperis et al. (2015). The Hartford and Liberty Mutual use 180 day and 90 day monitoring periods, respectively. http://hartfordauto.thehartford.com/landingpages/TrueLane/faqs.shtml. https://www.libertymutual.com/righttrack/righttrack-faq/righttrack-faq-review.

12 PHYD firms will continue to use other public data, such as gender, as well, unless firms are able to offer fully non-linear contracts based on observed driving variables. See Buzzacchi and Valletti (2005).
} 
approval from state regulators before introducing new prices. Furthermore, Guensler et al. (2004) surveyed state regulators in 2003, asking them whether PHYD insurance was allowable. Of the 43 representatives who responded, only 27 states reported that PHYD insurance programs were allowable.

A handful of other insurers followed suit after Progressive's launch of SnapShot, and Figure I shows the expansion of the five firms' PHYD insurance programs across all U.S. states. AllState introduced its program, DriveWise, in Illinois in 2010, in Arizona and Ohio in 2011, and in 44 additional states by 2014. State Farm was not far behind, introducing its InDrive program in 2011, and expanding to 45 states by 2014. Finally, The Hartford and Liberty Mutual introduced their programs in 2012, with The Hartford offering its PHYD insurance program (TrueLane) in 40 states by 2014 , and Liberty Mutual offering its program (RightTrack) in 29 states by $2014 .{ }^{13}$

Table I shows the order of PHYD insurance entry for each firm in each state that it entered. While Progressive was the first insurer to introduce its PHYD insurance program in most states, there still was some variation in which firm entered each state first, and more variation in which firm entered second. Progressive was the first to enter 41 states, State Farm was the first to enter four states, and AllState entered one state first. The distribution of the second entrant's identities is much less skewed.

Aggregate statistics about the take-up of PHYD insurance among consumers are difficult to find, but available statistics suggest that PHYD insurance has grown in popularity, and comprises a nonnegligible part of the market. A pair of 2014 surveys separately found that about nine percent of

\footnotetext{
${ }^{13}$ Some other insurers (e.g. GMAC/National General, MetroMile, and Travelers) offer prices based only on (approximate) mileage driven, but do not factor in behaviors like speeding, hard braking, etc. eSurance and SafeCo have also launched PHYD insurance programs. They are subsidiaries of AllState and Liberty Mutual, respectively.
} 
adult drivers in eligible states were enrolled in PHYD insurance programs. ${ }^{14}$ Another study predicts nearly 100 million drivers in Europe and the U.S. will be enrolled in PHYD insurance programs by $2020 .^{15}$

\subsection{Simple Indications of Pay-How-You-Drive Success}

PHYD insurance data have proven quite useful at predicting accident risk. For example, Progressive has found that a driver who brakes hard more than 8 times in 500 miles, defined as decelerating at least $8 \mathrm{mph}$ in one second, is $73 \%$ more likely to be involved in an accident (Scism, 2016). Using monitored driving behavior data, Ayuso et al. (2014) confirm that other monitored driving behaviors correlate with accident risk as well, and the results of Parry (2005) suggest that observed reductions in risk may be partially due to the role of monitoring in solving the moral hazard problem.

Because the algorithm and data collected from PHYD telematics devices are proprietary, the data may give a consumer's incumbent provider a competitive advantage. ${ }^{16}$ The incumbent provider can offer its low-risk drivers prices that are lower than can be reasonably offered by their competitors, who lack the incumbent provider's data to segment good from bad drivers. Progressive's CEO, Glenn Redwick, concurred, stating "You have a rate that truly reflects your

\footnotetext{
${ }^{14}$ See https://www.msn.com/en-us/money/autoinsurance/5-pay-as-you-drive-car-insurance-myths/arBB7QEZ7, and https://www.towerswatson.com/en/Insights/IC-Types/Survey-ResearchResults/2014/09/usage-based-insurance-2014-us-consumer-survey-infographic ${ }^{15}$ https://www.forbes.com/sites/sarwantsingh/2017/02/24/the-future-of-car-insurance-digital-predictiveand-usage-based/\#578a40ad52fb

${ }_{16}$ Progressive is not required to disclose PHYD insurance data to competitors. In fact, Progressive's privacy policy has explicitly prohibited sale of these data to 3rd parties. See Scism (2016). In addition, while Progressive was required to submit its PHYD insurance rating algorithm to regulators, it was never publicly revealed to anyone but the regulators, implying competitors could not directly copy it. See https://www.wsj.com/articles/SB10001424052748704433904576212731238464702.
} 
driving behavior... No one else can know that in the marketplace on a new quote." 17 He further noted that retention was $40 \%$ higher than typical "for those that get a substantial discount." It is true that entrants can duplicate these data by monitoring consumers themselves. But the explicit monitoring costs and consumers' corresponding disutility constitute switching costs which may provide the incumbent provider, Progressive in most states, an advantage even after competing PHYD programs enter.

In many cases, Progressive's PHYD discounted prices far exceed actuarially fair rates. Figure II confirms this, using national data for Progressive's SnapShot program, reported in a 2014 rate filing in Alaska. ${ }^{18}$ Progressive's PHYD insurance score ranges, their measure of relative risk for participants, are shown on the x-axis, from safe drivers to high-risk drivers. The circles in the figure denote loss ratios for each group, defined as loss ratio $=\frac{\text { payouts to beneficiaries }}{\text { earned premiums }}$, the firm's variable cost over its revenue. The figure shows that those drivers who receive the largest discounts also yield the highest margins for Progressive. The loss ratio for the lowest risk group - with PHYD insurance scores between 0 and 9 - is only $30.7 \%$, less than half of the industry average of $66 \%{ }^{19}$ Firms not monitoring consumers with telematics devices may not be able to offer such low rates to safe drivers because they lack data on driving habits needed to identify lowrisk consumers. Acquiring these data incurs additional monitoring costs on the both the competitor and switching consumers.

\footnotetext{
$17 \mathrm{http}: / /$ news.onlineautoinsurance.com/consumer/progressive-talks-future-with-snapshot-car-insuranceprogram-910470

18 See Alaska Serff tracking number SERF PRGS-129620997. https://filingaccess.serff.com/sfa/search/filingSummary.xhtml?filingId=129620997\#

${ }^{19}$ For sources of data on industry averages, see the data section. Progressive promised not to raise enrollees' rates beyond non-monitored rates for a long time, explaining why drivers identified as risky demonstrated loss ratios exceeding industry averages.
} 
The black-bordered rectangles in Figure II represent a histogram of earned premiums. They show that the low-risk groups comprise the majority of the premiums Progressive earns under the program, suggesting that most drivers fall into these low-risk groups. Accordingly, the firm's loss ratio under the PHYD insurance program, 56.9\%, is well below both Progressive's overall autoinsurance loss ratio (64.2\%) and the industry average (66\%) in 2014. This suggests that the PHYD insurance program could allow the incumbent to increase its margins on average. However, a more detailed analysis is needed to establish a causal connection, to estimate how profits vary with the extent of competition, and to determine whether these programs merely segment consumers, or also influence the decision to drive safely.

\section{Model}

Suppose there are two types of drivers: good drivers, and bad drivers, denoted $G$ and $B$, respectively. A driver of type $i$ imposes a per-period expected accident cost to the insurer of $A_{i}$, where $A_{G}<A_{B}$. For simplicity, we assume that good drivers can reduce their expected accident cost from $A_{G}$ to zero at cost of effort to the consumer equal to $r$, while the costs of effort for bad types $\left(r_{B}\right)$ to reduce accident risks to zero are prohibitively large. ${ }^{20}$ Hence we allow for adverse selection and heterogeneous moral hazard.

We assume, without loss of generality, that monitoring is costless for the firm. ${ }^{21}$ We also assume monitoring technology can effectively measure driving habits which imply zero accident risk. For

\footnotetext{
${ }^{20}$ In unreported calculations, we verify our main results hold when the cost of reducing accident cost to some safer level is larger for B than G types. Supporting this assumption, previous studies find moral hazard costs are heterogeneous (Einav et al., 2013) and positively correlated with an underlying tendency to drive recklessly (Zuckerman and Kuhlman, 2000).

21 The costs of monitoring can either be borne by drivers, or firms, or both. If allowing explicit monitoring cost $m$, the main results are identical, except $r$ is replaced in with $r+m$.
} 
simplicity, we assume the monitoring technology is unable to decipher from monitoring driving habits whether accident risk is $A_{G}$ or $A_{B}$, implying $G$ types cannot reveal their type without effort. ${ }^{22}$ But if the firm monitors and observes driving habits which imply zero accident risk, it can infer the driver was a type $G$ driver (exerting effort to drive safer). The firm can use this previously gathered information to subsequently target identified type $\mathrm{G}$ drivers.

We further assume a perfectly competitive market for insurance products which do not employ monitoring with a price of standard insurance of $\bar{A}=E\left[A_{i}\right]$, the expected accident $\operatorname{cost}^{23}$ Finally, price may change each period and firms and consumers are forward-looking with a discount rate $\delta$.

We let consumer utility be a linear function of the total implied price, i.e. the explicit price plus effort costs. Assuming the intrinsic utility of each insurance option is the same, and insurance is mandatory, this implies that utility maximizing consumers choose the insurance option which minimizes total implied price, including effort costs:

$$
C_{G, t}= \begin{cases}\bar{A} & \text { if never monitored } \\ P_{t}+r & \text { if currently monitored } \\ P_{t} & \text { if previously monitored }\end{cases}
$$

\subsection{PHYD Monopoly - A Single PHYD Insurance Provider}

If not monitored, the type $G$ consumer's price of insurance is $C_{g, t}=\bar{A}$. A monopolist PHYD provider will therefore offer a price which leads to a $C_{g, t}$ just below $\bar{A}$, provided profits remain

\footnotetext{
${ }^{22}$ It is analogous to assume that bad type drivers could and would pool with good type drivers by reducing their accident risk to $A_{G}$, if a discount were offered. In unreported calculations, we verified the main results can persist without such strong assumptions.

${ }^{23}$ Eventually, if Good type drivers migrate to a PHYD insurance program, a separating equilibrium ensues. Only Bad type drivers choose standard insurance, and the price of regular insurance will become $A_{B}$.
} 
positive. While monitored, PHYD consumers of type $\mathrm{G}$ will thus pay at most $P_{t}=\bar{A}-r$, incurring a total price $C_{G, t}$ (including effort costs) of $\bar{A}$. The firm earns per-consumer static profits equal to price:

$$
\pi_{t=1}^{M}=\bar{A}-r
$$

When no longer monitored, consumers no longer incur effort cost $r$, and the monopolist can charge up to $\bar{A}$. Thus in subsequent periods, the insurer yields static profits per identified $G$-type consumer, including accident cost $A_{G}$, equal to:

$$
\pi_{t>1}^{M, T}=\bar{A}-A_{G}
$$

The profits from continued monitoring are higher than temporary monitoring if and only if $r<$ $A_{G} \cdot{ }^{24}$ Note that a monopolist PHYD provider may profit whether or not past data are marginally useful. By assumption, past data are redundant and thus provide no additional information on a consumer's type when monitoring consumers permanently. Yet, a monopolist may still profit when electing to monitor consumers permanently. However, the same may not true for an incumbent competition.

\subsection{The Incumbent's Problem under Competition}

Suppose the incumbent subsequently faces competition from (many) new entrants. All firms are identical except for information asymmetries - entrants must monitor to infer a driver's type.

\footnotetext{
${ }^{24}$ If $r>\bar{A}$, the firm may still make positive long-run profits by ceasing monitoring, despite incurring negative profits in period $\mathrm{t}=1$.
} 
Entering firms set per-period prices equal to cost, 0 when monitoring, and $A_{g}$ after ceasing monitoring. The type G consumer's corresponding total long-run discounted prices, including effort costs, are $\frac{r}{1-\delta}$ under permanent monitoring, and $r+\frac{\delta A_{G}}{1-\delta}$ if they cease monitoring after one period. Surviving competitors offer the monitoring option with the lower total cost, which is permanent monitoring if and only if $r \leq A_{G}$.

The incumbent's profits are completely eliminated when previously gathered information is not marginally useful. This occurs when $r \leq A_{G}$, i.e. when effort costs of driving safer are weakly less than the reduction in expected accident costs. In that case, both incumbent and entrants use continuous monitoring to mitigate the moral hazard costs. Consumers thus incur effort costs whether or not they switch - switching costs are zero and the market is competitive regardless of relative costs.

On the other hand, the incumbent's profits may not be completely eliminated by competition when previously gleaned information is marginally useful. When $r>A_{G}$, effort costs exceed the reduction in accident costs, and firms would prefer not to permanently incentivize safer driving. Since entrants still must incur this cost to segment types, the incumbent - which has already done so - may maintain a competitive advantage. More precisely, type $G$ consumers incur a discounted total price of $r+\frac{\delta A_{G}}{1-\delta}$ if switching. Remaining with the incumbent is incentive compatible if the future discounted price $\left(\frac{P_{t}^{I}}{1-\delta}\right)$ is less, i.e. if $P_{t}^{I} \leq(1-\delta) r+\delta A_{G}$. The incumbent's price also must be weakly less than the price of standard insurance, $\bar{A}$. Thus, the incumbent's per-period profit per type $G$ consumer in subsequent periods is:

$$
\pi_{t>1}^{I, T}=\min \left(\bar{A},(1-\delta) r+\delta A_{G}\right)-A_{G}=\min \left(\bar{A}-A_{G},(1-\delta)\left(r-A_{G}\right)\right)
$$


Observation: Incumbent's static profits following entry may lie anywhere between zero and monopoly profits, depending on monitoring cost $r$.

This observation follows from Equation 3. It implies that the incumbent's per-period profits under competition in periods $t>1$ are at most zero when $r \leq A_{G}$. In this case, the incumbent would choose to monitor permanently, making past data redundant. But when $r \geq A_{G}$, past data are useful for segmenting consumers. The incumbent's profits under competition increase with $r$, but are bounded above by $\bar{A}-A_{G}$, the expression for monopolist's static profits after monitoring.

\subsection{Discussion}

Figure III illustrates the relationship between monitoring costs and the profits of the incumbent, both with and without competition. A single firm can benefit from gathering proprietary data, but competition may erode profits. If substantial moral hazard problems exist $\left(r \leq A_{G}\right)$, firms monitor continually regardless of market structure and order of entry, and prior information is redundant. In that case, competition drives the incumbent's profits to zero. By contrast, if the effort costs of monitoring are sufficiently high $\left(r>A_{G}\right)$, firms monitor only to segment consumers. In that case, the incumbent, which already has data to segment consumers, has an advantage over potential entrants - competition does not drive the incumbent's profits to zero.

If, as assumed in the model, there are no externalities, firms monitor consumers permanently if and only if continual monitoring is efficient, i.e. $r \leq A_{G}$. However, in many contexts, including auto insurance, there are externalities from risky driving which are borne by bystanders, and their insurers. When incorporating these externalities, a social planner might prefer permanent 
monitoring even when firms prefer temporary monitoring. Hence, firms may choose monitoring periods which are inefficiently short.

\section{Data}

The data used in this paper combine two categories of information: (i) PHYD insurance entry dates, and (ii) state-level, firm-specific revenue and loss data. Progressive and AllState representatives provided exact entry dates of their SnapShot and DriveWise programs, respectively, and The Hartford provided entry years for their TrueLane program. Entry years for State Farm's InDrive program and Liberty Mutual's RightTrack were found from news articles and historic versions of their websites, using the Wayback Machine. To be consistent across insurers, we collapsed entry dates to the yearly level. Entry patterns are described in detail in Section 2.

The PHYD insurance entry dates were merged with data provided by the National Association of Insurance Commissioners. The latter data include annual private insurance premiums, losses, and containment costs for auto insurance (NAIC, lines 19.1, 19.2 and 21.1), for each insurer in each state between 2008 and 2014. We further supplement these datasets with information on traffic safety and car accidents from the Fatality Analysis Reporting System (FARS) by the National Highway Traffic Safety Administration, which we describe in more detail in Section 6.

The structure and accounting details of the auto insurance industry require that we make a few adjustments to the raw data. First, there have been several mergers in the insurance industry between 2008 and 2014. To address this issue, we restrict our data to the top 25 firms by domestic 
auto insurance revenues, completing a thorough search for mergers among these. ${ }^{25} \mathrm{We}$ consider revenues and costs of the final, merged firms in this paper, even in periods prior to the merger. Second, while earned premiums and losses are reported accurately in most states, Michigan has serious reporting issues arising from anomalies in their laws. This leads to unusually large variation in profits, and inaccurate reporting. ${ }^{26} \mathrm{We}$ therefore drop all observations pertaining to the state of Michigan.

\subsection{Revenues and Profits}

Insurance premiums include payments from consumers less commissions paid to insurance brokers. We will subsequently refer to these as revenues, and denote firm $j$ 's revenues in state $s$ and year $t$ as $R_{j s t}$. An insurance company's variable costs consist of incurred losses, which are the paid claims and loss reserves of the company, and the containment costs - costs of investigating claims as well as any related litigation expenses. We construct state-level yearly (variable) profits $\pi_{j s t}$ for each firm, as earned premiums (revenues) minus the sum of claim payments and containment costs. Note these insurer/state/ yearly level profits include profits from multiple types of auto insurance, including standard products as well as PHYD programs.

Revenue and profit are log-linearly distributed across firms. In 2008, State Farm and AllState were the largest insurers, with State Farm earning the largest revenue, at $\$ 28.6$ billion, and AllState earning the largest operating profit with $\$ 7.7$ billion. The $25^{\text {th }}$ largest company (Sentry) earns much

\footnotetext{
${ }^{25}$ Mergers and acquisitions were found using SNL financial data and internet searches.

${ }^{26}$ The loss ratios that Michigan auto insurers report for no-fault coverage differ wildly across insurers. As a result, NAIC is not able to include the profitability of Michigan no-fault insurance in its survey. See http://www.cpan.us/docs/Angoff_Report_Profitability_and_Pricing_in_Michigan_Auto_Insurance_Market.pdf.
} 
less than the largest companies, with a revenue of $\$ 906$ million. On average, the 25 largest firms earned $\$ 5.45$ billion in revenue and incurred total costs of $\$ 3.61$ billion in $2008 .{ }^{27}$ By 2014 , these numbers have increased to $\$ 6.25$ billion and $\$ 4.31$ billion, respectively, for an increase in variable profits from $\$ 1.85$ to $\$ 1.95$ billion.

Four of the five companies which offered PHYD insurance programs were among the largest six insurers before the arrival of these programs. The other PHYD provider, The Hartford, was the eleventh largest company in terms of revenue in 2008.

\section{Empirical Strategy and Results}

PHYD insurance introduction varies across both insurance companies and states. We exploit this fact by employing a difference-in-differences analysis. Specifically, our analysis compares the change in a firm's yearly state profits after introducing PHYD insurance in that state to changes in yearly state profits of other non-PHYD firms in the same state. Additionally, we control for changes in the same firm's profits in other states in which they had not yet introduced PHYD insurance. Formally, we estimate different specifications of the following general form:

$$
\pi_{j s t}=\beta_{0}+\beta_{1} P H Y D_{j s t}+\beta_{2} \times P H Y D_{j s t} \times N u m C_{o m p}+\mu_{j t}+v_{j s}+\eta_{s t}+\epsilon_{j s t}
$$

where $\pi_{j s t}$ is firm $j$ 's profit in state $s$ and year $t, P H Y D_{j s t}$ is an indicator which equals one if firm $j$ has introduced PHYD insurance in that state, and NumComp $p_{s t}$ indicates the number of

27 The costs consist of mostly of the incurred losses, with only about $4 \%$ of the costs coming from claims investigations and related litigation expenses. 
competing firms which have PHYD insurance programs in the state. The remaining controls, $\mu_{j t}$, $v_{j s}$, and $\eta_{s t}$, are firm-year, firm-state, and state-year pair fixed effects, respectively.

Note this setup differs slightly from typical difference-in-differences specifications - our statefirm-year panel allows a more robust set of controls. Like standard difference-in-differences specifications, we use non-treated firms to control for changes in profits in the state over time unrelated to the treatment. We thus account for the impact of time-varying state regulations, market structure, extraneous factors like inclement weather in certain years, etc. We also use firmstate fixed to account for level differences across firms, separately by state. Additionally, our specification includes firm-year fixed effects, which use changes in profits in states in which the firm had not introduced PHYD insurance to control for divergence between treated and untreated firms that would have occurred even in the absence of PHYD insurance programs.

After controlling for these differences, the coefficient $\beta_{1}$ identifies the change in profits that is due to the introduction of PHYD insurance by a company in that state, and $\beta_{2}$ the impact of competition from entering PHYD insurance firms. From the estimates of $\beta_{1}$ and $\beta_{2}$, we infer whether proprietary data are useful for segmenting consumers, and whether past data provide a lasting competitive advantage for incumbent providers. We discuss identification further in Section 5.3.

Because we expect the impact of PHYD insurance on profits to be proportional to revenues, and because there are substantial differences in revenues across states and insurers, interpretation of the effect is difficult when using untransformed profits as the outcome measure. We account for these differences by normalizing profits by the insurer's average annual revenues in the state during the observed period. That is, our transformed dependent variable is $\pi_{j s t}=\frac{\pi_{j s t}^{*}}{\bar{R}_{j s}}$, where $\pi_{j s t}^{*}$ is firm $j$ 's untransformed profit in state $s$ and year $t$, and $\bar{R}_{j s}$ is firm $j$ 's average revenue in state 
$s$ across all years. This normalization allows for negative profits which are expected in insurance markets, where costs are potentially large and inherently random $-1.5 \%$ of the observations in our estimation sample exhibit negative profits. The average normalized profit is 0.35 .

\subsection{Baseline Estimation - PHYD Insurance, Profits, and Competition}

Table II shows the estimated effect of introducing PHYD insurance on a firm's normalized profits, distinguishing between different PHYD insurance entry positions and the number of PHYD insurance competitors. In column (1), we report estimates of the effect of PHYD insurance independent of how many firms already offer PHYD insurance. These results suggest that firms do not consistently profit from introducing PHYD insurance programs. Estimating separate effects by order of entry, in column (2), reveals that the first firm which introduces PHYD insurance in a state increases its profit significantly, whereas later entrants do not significantly profit.

We next explore the impact of time and competition. Column (3) flexibly controls for competition by including an indicator variable for each number of entrants. The negative coefficient on an indicator for 3 or 4 firms competing with the incumbent is significant at the $10 \%$ level, and the point estimate is of similar magnitude to the coefficient on the indicator for the incumbent's entry. At the mean normalized profit level of 0.322 among incumbent PHYD insurers, the results in column (3) suggest that introducing a PHYD insurance program initially increases profits by $14 \%$, but the profit gain is reduced to less than $1 \%$ after four or five firms have entered. Column (4) adds a control for time since the incumbent entered. The coefficient on time since entry is positive albeit insignificant, and the coefficient on competition by 3 or 4 firms remains negative, and is significant at the 5\% level. These results indicate that competition from 3 or 4 firms significantly 
lowers profits, and may be sufficient to erode the incumbent's supernormal profits, whereas time alone does not erode profits.

These results are consistent with both adverse selection and low costs of being monitored, following the intuition from our model in Section 3. The fact that an incumbent (typically) monitoring for short periods continues to profit as long as no competitors enter suggests previously collected data are effective for segmenting consumers. But since competition erodes profits, the data do not give the incumbent a lasting competitive advantage, implying competitors can duplicate the relevant data at reasonably low cost.

\subsection{Robustness}

Our data structure and the timing of events could give rise to interpretation concerns. For example, Progressive is the first firm to introduce PHYD insurance in 41 U.S. states. It is possible that we measure the impact of introducing PHYD insurance on Progressive's profits, rather than the impact of introducing PHYD insurance on profits for other firms when they are the first firm to enter.

We address this concern in Table III. In the first column, we interact our first-to-enter indicator with a second indicator that is turned on if the entrant is Progressive, to explore whether the estimated impact is driven mostly by that firm. The main coefficient, PHYD insurance entry by the first entrant, remains positive and significant. This suggests our results are not driven by one firm, Progressive Insurance.

In columns (2) and (3) of Table III we explore alternative transformations of the dependent variable. In column (2) we use the log of firm profits, dropping observations with negative profits. Because dropping observations with negative profits may bias results, we also use the asinh 
transformation (Burbidge et al., 1988) of profits in column (3). Both transformations yield similar results to the main specification: introducing a PHYD insurance program increases profits, at least for the first firm to enter. Competition is not found to reduce profits in the $\log$ (profits) specification, presumably because observations with negative profits are dropped, biasing towards zero coefficients on variables which cause lower profits, including the extent of competition.

\subsection{Identification}

While our results are robust to a wide set of specifications, one might remain concerned that firms may introduce PHYD insurance programs in states where profits were expected to increase even in the absence of a PHYD insurance program. This would lead to an overestimate of the impact of PHYD insurance introduction on profits, and an underestimate of the impact of competition. However, such concerns do not appear to be driving the results.

Our difference-in-differences specification alleviates the most obvious endogeneity concerns. First, "treated" firms, i.e. those which introduced PHYD insurance programs, might have systematically different time trends from "non-treated" firms. Variation in when and if treated firms entered each state allows us to include firm-year fixed effects to control for company specific trends. Second, firms could enter states anticipated to be more profitable in general, whether or not PHYD insurance is introduced. State-year fixed effects, which are identified by the profitability of firms with no (current) PHYD insurance programs in the state, control for such differences.

Therefore, endogeneity is only a concern if the introduction of PHYD insurance coincides with strong positive profit shocks that apply only to the state and PHYD insurance firm. We believe 
this is unlikely, for two reasons. First, if firms endogenously chose to introduce PHYD programs in states where higher profits were anticipated, we would expect this to apply not only to the first entrant, but also to subsequent entrants. However, as Table II shows, only the first to enter profits significantly. Second, PHYD insurance programs were planned in advance and rolled out very quickly. For example, between 2008 and 2010, Progressive's annual report stated plans to introduce PHYD insurance in the following year in 12-15 states, 15 states, and 15 states, respectively, at least partially depending on regulatory approval. ${ }^{28}$ In line with the verbiage in their annual reports, firms appear to focus on rapid expansion, rather than selecting a subset of particular states.

Perhaps a more important concern, because the theoretical model gives ambiguous predictions about whether competition erodes incumbent profits, is whether the impact of competition is biased. If competitors entered states concurrent with positive transient shocks to the profitability of PHYD insurance programs, the positive shock would presumably apply to the incumbent's profits as well, somewhat offsetting the decline in the incumbent's profits from increased competition. Hence, if we did not find that competition lowers profits, one might be concerned the result might be attributed to endogeneity concerns. But we did. We find that three or four competitors (four of five PHYD insurance firms in total) substantially reduce the incumbent's profits.

As an additional test for these concerns, we investigate whether endogenous factors impact entry timing using monthly, state-specific Google search volume for the phrase "Progressive Car

\footnotetext{
${ }^{28} \mathrm{http}: / /$ media.corporate-ir.net/media_files/irol/81/81824/pdf/ar/Progressive2008-FinancialReview.pdf http://media.corporate-ir.net/media_files/irol/81/81824/pdf/ar/Progressive2009-FinancialReview.pdf http://media.corporate-ir.net/media_files/irol/81/81824/pdf/ar/Progressive2010-FinancialReview.pdf
} 
Insurance," using Google Trends data. ${ }^{29}$ Our attention is restricted to Progressive, because it entered 41 states first, and firms entering second or later are not found to increase their profits. We regress search volume on date and state fixed effects, and we plot the residuals against the months since Progressive introduced PHYD insurance in the respective states in Figure IV. Note that search volume does not appear to increase leading up to or soon after PHYD insurance introduction, suggesting that PHYD insurance introduction was not timed to coincide with increasing awareness in Progressive's auto insurance products. ${ }^{30}$

If endogeneity doesn't explain entry, what does? To explore entry-timing decisions among the five PHYD insurance firms, we employ a Cox proportional hazards model, controlling for each firm's yearly tendency to introduce PHYD insurance programs. First, we investigate state-level laws. In column (1) of Table IV, we relate entry timing to whether the regulator surveyed by Guensler et al. (2004) believed PHYD insurance programs abided by state laws in 2003 . In column (2), we relate entry timing to whether insurers needed to obtain prior approval from state insurance regulators before altering their pricing (Hunter, 2008). Proportional hazard ratios (estimated relative odds) are reported in place of coefficients. The impacts are large and consistent with our expectations. Firms are 66\% more likely in a given year to introduce PHYD insurance programs in states in which regulators believed PHYD insurance abided by state laws in 2003, and slower to introduce PHYD insurance in states which required prior approval for any price changes based on a 2008 assessment. These analyses confirm regulatory environments strongly influenced entry timing. Columns (3) and (4) consider the impact of incumbent firms on entry. The likelihood of a firm introducing a PHYD insurance program is inversely correlated with the number of

\footnotetext{
29 The data are normalized so the highest search volume in any state equals 100.

${ }^{30}$ To be sure, we included each firm's state-specific annual search volume in unreported profit regressions, finding that these additional controls have no meaningful effect on the coefficients of interest.
} 
existing PHYD insurance firms in the state, which is consistent with the contention that later entrants profit less from PHYD insurance programs, and thus firms were presumably less inclined to enter after another firm had already entered the state.

\subsection{Mechanism behind Profit Increases}

It seems clear that the first firm to utilize PHYD insurance can profit from the additional information about consumers. It is not clear yet whether this advantage is driven by additional demand - holding markups relatively constant - or by increases in efficiency, holding revenues relatively constant. We examine this by measuring the impact of introducing PHYD insurance on earned premiums and cost measures separately. We specifically consider two variables: (i) revenues, again normalized by the firm's mean revenue in the same state over the seven observed years, and (ii) the fraction of earned premiums (revenues) used to pay claims and associated litigation costs. ${ }^{31}$

The results are shown in Table V. The point estimates have sensible signs. Column (1) reports results from a regression of normalized revenues on PHYD insurance entry and the extent of competition faced by the incumbent. The coefficient on PHYD insurance entry by the first firm is statistically insignificant, although its positive sign might suggest higher revenues. Column (2) presents the results from an analogous regression with the ratio of costs to revenues as the dependent variable. The coefficient on PHYD insurance entry by the first firm is negative and significant at the $10 \%$ level, implying PHYD insurance entry, as least by the first firm, lowers

\footnotetext{
31 This ratio is often referred to as the DCC (Defense and Cost Containment) ratio
} (http://www.naic.org/consumer_glossary.htm) 
costs per dollar of earned premiums. Said another way, PHYD programs increase markups. Specifically, the point estimates suggest that introducing a PHYD program first in a state reduces the entire firm's cost ratio by 0.038 . This implies costs per dollar of revenue fall $6 \%$ relative to the median cost ratio of 0.63 , even though reported cost ratios include other non-PHYD programs also offered by the insurer. This suggests incumbent PHYD providers were able to segment lowerrisk drivers, yet charge them rates above the actuarially fair rate.

\section{Consumer Behavior and Broader Implications}

If firms monitor for short periods and use previously gathered data to segment inherently good from bad drivers, then these programs offer no societal benefits after the monitoring period. Rather, they enable PHYD insurers to extract a larger share of a fixed surplus. On the other hand, if these programs alleviate moral hazard problems by monitoring and incentivizing safer driving, then the impacts of PHYD insurance may extend beyond rent seeking and yield tangible impacts by reducing accidents. Since a driver does not internalize the costs their dangerous driving may impose on bystanders and bystanders' insurers, explicit rewards for safer driving through PHYD insurance programs may also address an externalities problem. However, only ongoing data collection - not data collected in the past - offers a permanent solution to these moral hazard and externalities problems.

To investigate whether PHYD insurance programs reduce accidents, we employ information on traffic safety from the Fatality Analysis Reporting System (FARS), which reports annual fatal accidents by accident and vehicle registration location (state). Fatal accidents provide an auspicious context because many of the monitored driving behaviors, such as driving in excess of 
$80 \mathrm{mph}$, hard breaking, and mileage (which is heavily influenced by driving on interstate highways), relate to chances of being in the most serious kinds of accidents. On average, 0.21 cars are involved in fatal accidents per thousand registered vehicles annually between 1995 and 2014, although this number has decreased substantially over recent decades, from 0.25 in 1995 to 0.16 in 2014.

We first estimate the impact of PHYD insurance on fatal accidents in a fixed effects panel estimation with measures of the state-level penetration of PHYD insurance as the independent variable of interest. Formally, we estimate

$$
\ln (\text { Vehicles in Fatal Accidents })_{s t}=\beta_{0}+\beta_{1} P H Y D_{s t}+\beta_{2} \ln (\text { Vehicles })_{s t}+\mu_{s}+\eta_{t}+\epsilon_{s t} \text {, }
$$

Where $s$ denotes the state in which the car is registered (including DC), and $t$ denotes the year. $\mu_{s}$ and $\eta_{t}$ are state and year fixed effects, respectively, and $P H Y D_{s t}$ is a measure of PHYD insurance penetration in state $s$ and year $t . \ln (\text { Vehicles })_{s t}$, a control variable, indicates the $\log$ number of registered vehicles. We first regress log-accidents on the cumulative number of firms which have introduced PHYD insurance programs in state $s$. We then explore whether safer driving is short-lived, given that drivers are only monitored for short periods of time in some PHYD insurance programs, and might eventually resume unsafe driving.

Table VI shows the coefficients of interest from these regressions. The results in column (1) imply that one more firm offering PHYD insurance would decrease the number of vehicles involved in fatal accidents by approximately 1.6\%. Since nine percent of drivers had enrolled in PHYD insurance by 2014, and there were 2.88 firms offering PHYD programs per state in the beginning of 2014 , on average $\frac{9 \%}{2.88}=3.125 \%$ of all drivers were enrolled with a given insurer's PHYD 
program. ${ }^{32}$ A back of the envelope calculation thus implies an average driver reduced his/her risk of being involved in a fatal accident by $\frac{1.6}{3.125}=0.51$, i.e. $51 \% .^{33}$ This finding, while strong, is in line with previous research. Weisburd (2015), using a pseudo-natural experiment, finds drivers are involved in $25 \%$ fewer accidents when their expected direct financial costs in the event of an accident are $\$ 235$ higher.

Column (2) of Table VI suggests the benefits are to some extent short-lived. PHYD insurance programs reduce accidents most in the first few years after being introduced. But coefficients for more than three years since entry are small and statistically insignificant. This suggests that monitoring in PHYD insurance programs encourages safer driving, but the benefits eventually fade after monitoring ceases or consumers stop being as attentive of their driving habits. Hence monitoring programs appear to incentivize costly effort, rather than developing safer driving habits through practice and instruction.

One might be concerned that contemporaneous changes at the state level may coincide with the introduction of PHYD insurance. To address this concern, we divide accidents by both the accident location and the state in which the involved vehicle was registered. ${ }^{34}$ This allows us to control for state-level accident risk. Intuitively, any state-level road-safety measures that coincide with PHYD insurance entry should only reduce in-state accidents. For example, suppose Alabama improves visibility on highways by adding lights around the time PHYD insurance programs are introduced in the state. Better lighting might explain reduced accidents in Alabama, but should

\footnotetext{
32 See https://www.msn.com/en-us/money/autoinsurance/5-pay-as-you-drive-car-insurance-myths/arBB7QEZ7. A survey by Towers Watson found similar percent of drivers using PHYD insurance: https://www.towerswatson.com/en/Insights/IC-Types/Survey-Research-Results/2014/09/usage-basedinsurance-2014-us-consumer-survey-infographic

33 The $90 \%$ confidence interval ranges from an $8.2 \%$ to a $94.2 \%$ risk reduction.

${ }^{34}$ Accidents involving vehicles registered in two (or more) states will appear twice (or more) as separate observations, one for each location of registry.
} 
not explain reduced accidents involving vehicles registered in Alabama that occur out of state. PHYD insurance availability, however, depends not on where a vehicle is located at a given moment, but rather on where it is registered. Hence, if the number of accidents involving cars registered in Alabama but occurring in Texas falls after PHYD insurance programs are introduced in Alabama, we can attribute the reduced risk to PHYD insurance.

Following this reasoning, we regress the log number of vehicles in fatal accidents in state $l$ that were registered in state $s$ on PHYD insurance entry in registry state $s$ :

$$
\ln (\text { Vehicles in Fatal Accidents }+1)_{l s t}=\beta_{0}+\beta_{1} P H Y D_{s t}+\beta_{2} \ln (\text { Vehicles })_{s t}+\kappa_{l s}+\gamma_{l t}+\epsilon_{l s t} \text {, }
$$

where $l$ denotes the accident location, $s$ denotes the vehicle's registration location, and $t$ denotes

the year. $\kappa_{s l}$ and $\gamma_{l t}$ are fixed effects added to control for registry/accident location pairs and accident state/year pairs. By including controls for accident frequencies in each state $\gamma_{l t}$, we explicitly control for state-specific developments in safety which may coincide with PHYD insurance introductions.

The results are shown in column (3) of Table VI. The results are consistent: PHYD insurance programs significantly reduce the number of vehicles involved in fatal accidents in the first few years after introduction. ${ }^{35}$

\section{Conclusion}

A firm which collects proprietary consumer information may achieve supernormal profits by targeting profitable consumers or encouraging low-cost behavior. But the competitive advantage

35 We yield similar results when omitting cars involved in accidents in their home state. 
lasts only if competitors cannot easily collect similar information. Incumbents might elect to monitor consumers for short periods, after which consumers face switching costs if moving to a competing firm. Such a strategy can allow the incumbent to retain supernormal profits even after competitors enter, but it may not be socially efficient. In the case of auto insurance, monitoring for only short periods may be followed by a return to unsafe driving and an inefficiently high number of accidents.

Empirically, we find that competition by three or four entrants (four of five firms in total) seems sufficient to eliminate the incumbent's rents from PHYD insurance programs, though we caution that this finding may be industry specific. Our finding that competition substantially reduces profits, coupled with the fact that Progressive - the first firm to introduce its PHYD program most states - employs temporary monitoring, suggests monitoring costs are low, yet large enough to discourage continuous monitoring. We also find that PHYD insurance programs lead to an economically meaningful reduction in the number of accidents, but these benefits dissipate over time.

Our paper thus provides evidence to help guide two major policy concerns. Our theoretical model suggests collecting proprietary data by monitoring one's own consumers might prevent competition from restoring market efficiency, suggesting antitrust laws might need to be updated in a world with widespread monitoring. However, empirically in the context of auto insurance, we find competition does suffice to reduce incumbent's supernormal rents.

Second, the decrease in accident risk (by 50\% among monitored drivers) is economically significant. If risky driving imposes externalities on insurers and bystanders, permanent monitoring may improve social welfare. Furthermore, without monitoring, firms may set inefficiently large incremental markups for low deductible plans, because insurers anticipate that 
high-risk consumers will disproportionally select low deductible plans (Puelz and Snow, 1994; Spence, 1973). ${ }^{36}$ With monitoring, firms can condition prices on driving behaviors, eliminating these selection issues. Monitoring thus enables insurers to charge efficient incremental markups for low deductible plans.

Finally, while increased monitoring might exacerbate privacy concerns, Acquisti et al. (2016) have found that by revealed preference consumers have a relatively low value for privacy. The benefits from monitoring, at least in some contexts, may appear to outweigh privacy concerns. Hence, there may be compelling arguments for regulations mandating monitoring or expanding incentives encouraging monitoring programs, at least in some contexts.

36 While insurers might alter their menu of contracts if adverse selection is addressed by PHYD insurance plans, the rigid nature of discounts observed empirically did not allow PHYD insurance to address this market failure during the time-period under investigation. 


\section{References}

Acquisti, Alessandro, Curtis Taylor, and Liad Wagman. "The Economics of Privacy." Journal of Economic Literature 54, no. 2 (2016): 442-492.

Ayuso, Mercedes, Montserrat Guillén, and Ana María Pérez-Marín. "Time and distance to first accident and driving patterns of young drivers with pay-as-you-drive insurance." Accident Analysis \& Prevention 73 (2014): 125-131.

Bresnahan, Timothy F., and Peter C. Reiss. "Entry and competition in concentrated markets." Journal of Political Economy 99, no. 5 (1991): 977-1009.

Burbidge, John B., Lonnie Magee, and A. Leslie Robb. "Alternative transformations to handle extreme values of the dependent variable." Journal of the American Statistical Association 83, no. 401 (1988): 123-127.

Buzzacchi, Luigi, and Tommaso Valletti. "Strategic Price Discrimination in Compulsory Insurance Markets.” The Geneva Risk and Insurance Review 30, no. 1 (2005): 71-97.

Dranove, David, and Ginger Zhe Jin. "Quality disclosure and certification: Theory and practice." Journal of Economic Literature 48, no. 4 (2010): 935-963.

Dubé, Jean-Pierre, and Sanjog Misra. "Scalable price targeting." No. w23775. National Bureau of Economic Research, (2017).

Einav, Liran, Amy Finkelstein, Stephen P. Ryan, Paul Schrimpf, and Mark R. Cullen. "Selection on moral hazard in health insurance." The American economic review 103, no. 1 (2013): 178-219.

Guensler, Randall, Adjo Amekudzi, Jennifer Williams, Shannon Mergelsberg, and Jennifer Ogle. "Current state regulatory support for Pay-As-You-Drive automobile insurance options." Journal of Insurance Regulation 21, no. 3 (2003): 31.

Hunter, J. Robert. "State Automobile Insurance Regulation: A National Quality Assessment and In-Depth Review of California's Uniquely Effective Regulatory System." Consumer Federation of America (April 2008) (2008): 8. 
Karapiperis, D., A. Obersteadt, A. Brandenburg, S. Castagna, B. Birnbaum, A. Greenberg, and R. Harbage. "Usage-based insurance and vehicle telematics: insurance market and regulatory implications." CIPR Study Series 1 (2015): 1-79.

Klein, Tobias J., Christian Lambertz, and Konrad O. Stahl. "Market transparency, adverse selection, and moral hazard." Journal of Political Economy 124, no. 6 (2016): 1677-1713.

Klemperer, Paul. "Markets with consumer switching costs." The Quarterly Journal of Economics 102, no. 2 (1987): 375-394.

- - . "Competition when consumers have switching costs: An overview with applications to industrial organization, macroeconomics, and international trade." The Review of Economic Studies 62, no. 4 (1995): 515-539.

Parry, Ian WH. "Is Pay-as-You-Drive insurance a better way to reduce gasoline than gasoline taxes?." American Economic Review (2005): 288-293.

Puelz, Robert, and Arthur Snow. "Evidence on adverse selection: Equilibrium signaling and cross-subsidization in the insurance market." Journal of Political Economy 102, no. 2 (1994): 236-257.

Rossi, Peter E., Robert E. McCulloch, and Greg M. Allenby. "Hierarchical modelling of consumer heterogeneity: an application to target marketing." In Case Studies in Bayesian Statistics, Volume II, pp. 323-349. Springer, New York, NY, 1995.

Rossi, Peter E., Robert E. McCulloch, and Greg M. Allenby. "The value of purchase history data in target marketing." Marketing Science 15, no. 4 (1996): 321-340.

Schneider, Henry. "Moral hazard in leasing contracts: Evidence from the New York City taxi industry." The Journal of Law and Economics 53, no. 4 (2010): 783-805.

Scism, Leslie. "Car Insurers Find Tracking Devices Are a Tough Sell." The Wall Street Journal. Jan 10, 2016. http://www.wsj.com/articles/car-insurers-find-tracking-devices-are-atough-sell-1452476714

Shiller, Benjamin Reed. "First-Degree Price Discrimination Using Big Data." (2016). 
Spence, Michael. "Job market signaling." The quarterly journal of Economics 87, no. 3 (1973): 355-374.

Waldfogel, Joel. "First degree price discrimination goes to school." The Journal of Industrial Economics 63, no. 4 (2015): 569-597.

Weisburd, Sarit. "Identifying moral hazard in car insurance contracts." Review of Economics and Statistics 97, no. 2 (2015): 301-313.

Zuckerman, Marvin, and D. Michael Kuhlman. "Personality and risk-taking: common bisocial factors." Journal of personality 68, no. 6 (2000): 999-1029. 


\section{Tables and Figures}

Table I: Order of PHYD insurance entry by insurer

\begin{tabular}{llllll}
\hline & \multicolumn{5}{c}{ Number states insurer was $n^{\text {th }}$ to introduce PHYD insurance } \\
\cline { 2 - 6 } Order of entry & AllState & The Hartford & Liberty Mutual & Progressive & State Farm \\
\hline 1 & 1 & 0 & 0 & 41 & 4 \\
3 & 10 & 5 & 1 & 1 & 15 \\
4 & 11 & 7 & 3 & 5 & 17 \\
5 & 14 & 15 & 8 & 1 & 6 \\
& 2 & 15 & 23 & 0 & 2 \\
\hline
\end{tabular}

Note: Any insurers entering the state in the same year were considered tied. In such cases, all tied insurers were assigned the highest entry order. For example, if AllState and Progressive each entered a state in the same year, and there were no preexisting PHYD insurance firms there, then both would be assigned an entry order of two, the second to arrive. 
Table II: Baseline estimation: PHYD insurance, order of entry, and profits

\begin{tabular}{|c|c|c|c|c|}
\hline \multirow{3}{*}{ Entered PHYD } & \multicolumn{4}{|c|}{ Dependent variable is normalized profit } \\
\hline & $(1)$ & $(2)$ & $(3)$ & $(4)$ \\
\hline & $\begin{array}{c}0.0062 \\
(0.0086)\end{array}$ & & & \\
\hline \multicolumn{5}{|l|}{ Entry order } \\
\hline $1^{\text {st }}$ & & $\begin{array}{l}0.0380^{* *} \\
(0.0179)\end{array}$ & $\begin{array}{l}0.0466^{* *} \\
(0.0186)\end{array}$ & $\begin{array}{c}0.0491^{* * *} \\
(0.0183)\end{array}$ \\
\hline $2^{\text {nd }}$ & & $\begin{array}{c}0.0187 \\
(0.0165)\end{array}$ & & \\
\hline $3^{\text {rd }}$ & & $\begin{array}{c}-0.0211 \\
(0.0158)\end{array}$ & & \\
\hline $4^{\text {th }}$ & & $\begin{array}{c}-0.0089 \\
(0.0158)\end{array}$ & & \\
\hline $5^{\text {th }}$ & & $\begin{array}{c}-0.0097 \\
(0.0185)\end{array}$ & & \\
\hline \multicolumn{5}{|c|}{$\begin{array}{l}\mathrm{I}(\text { Entered and } 1 \text { st }) \times \\
\mathrm{I}(n \text { competitors })\end{array}$} \\
\hline$n=1$ & & & $\begin{array}{l}-0.0120 \\
(0.0228)\end{array}$ & $\begin{array}{c}-0.0224 \\
(0.0254)\end{array}$ \\
\hline$n=2$ & & & $\begin{array}{l}-0.0145 \\
(0.0267)\end{array}$ & $\begin{array}{c}-0.0272 \\
(0.0264)\end{array}$ \\
\hline$n=3$ or 4 & & & $\begin{array}{c}-0.0438^{*} \\
(0.0265)\end{array}$ & $\begin{array}{c}-0.0620^{* *} \\
(0.0289)\end{array}$ \\
\hline $\begin{array}{l}\text { Years since } \\
\text { entry }\end{array}$ & & & & $\begin{array}{c}0.0075 \\
(0.0081)\end{array}$ \\
\hline Observations & 6072 & 6072 & 6072 & 6072 \\
\hline
\end{tabular}

Notes: The table reports coefficients for a difference-in-differences estimation with state-insurer, state-year, and year-insurer pair fixed effects. The dependent variable is profit normalized by the firm's average revenues in that state. Robust standard errors (reported in parentheses) are used to account for heteroskedasticity arising from differences in the number insured across observations, which, by the law of large numbers, impacts the variance of our normalized profit variable. ${ }^{*} \mathrm{p}<0.1,{ }^{* *} \mathrm{p}<0.05,{ }^{* * *} \mathrm{p}<0.01$ 
Table III: Robustness checks and alternative specifications

\begin{tabular}{|c|c|c|c|}
\hline & (1) & (2) & (3) \\
\hline & \multicolumn{3}{|c|}{ Dependent variable is: } \\
\hline & $\begin{array}{l}\text { Normalized } \\
\text { profit }\end{array}$ & Log(profit) & Asinh(profit) \\
\hline Entered and $1^{\text {st }}$ & $\begin{array}{c}0.101^{*} \\
(0.0566)\end{array}$ & $\begin{array}{l}0.0624^{*} \\
(0.0375)\end{array}$ & $\begin{array}{l}0.777^{* *} \\
(0.324)\end{array}$ \\
\hline $\begin{array}{l}\text { I }(\text { Entered and } 1 \text { st }) \times \\
\text { \# competitors }\end{array}$ & $\begin{array}{l}-0.0116 \\
(0.0079)\end{array}$ & $\begin{array}{c}0.0078 \\
(0.0142)\end{array}$ & $\begin{array}{l}-0.323 \\
(0.217)\end{array}$ \\
\hline Entered $1^{\text {st }} \mathrm{x}$ I(Progressive) & $\begin{array}{l}-0.0706 \\
(0.0548)\end{array}$ & & \\
\hline Observations & 6072 & 5980 & 6072 \\
\hline
\end{tabular}

Notes: The table reports coefficients for a difference-in-differences estimation with state-insurer, state-year, and year-insurer pair fixed effects. The dependent variable is profit normalized by the firm's average revenues in that state. Robust standard errors (reported in parentheses) are used to account for heteroskedasticity arising from differences in the number insured across observations. ${ }^{*} \mathrm{p}<0.1,{ }^{* *} \mathrm{p}<0.05,{ }^{* * *} \mathrm{p}<0.01$ 
Table IV: Relative odds of introducing PHYD insurance programs, 2008-2014

\begin{tabular}{lllll}
\hline & \multicolumn{3}{c}{ PHYD insurance entry } \\
\cline { 2 - 4 } & \multicolumn{1}{c}{$(1)$} & $(2)$ & $(3)$ & \\
\hline State allowed PHYD 2003 & $1.668^{* * *}$ & $1.657^{* * *}$ & \\
& $(0.237)$ & $(0.236)$ & \\
Prior approval required & & $0.733^{*}$ & & \\
for rate changes & $(0.117)$ & & \\
Previous PHYD entrants & & $0.664^{* *}$ & \\
One PHYD entrant & & $0.112)$ & $(0.224)$ \\
& & & $0.303^{* *}$ \\
Two PHYD entrants & & & $(0.165)$ \\
Three PHYD entrants & & & $0.297^{* *}$ \\
& & & $(0.178)$ \\
Four PHYD entrants & & & $0.111^{* * *}$ \\
& & & $(0.087)$ \\
\hline Observations & & & 1453 \\
\hline
\end{tabular}

Note: The table reports the results of a Cox hazards model predicting firms' introduction of PHYD insurance programs in each state. The event variable is an indicator variable noting entry of firm $j$ in year $t$ in state $s$. Hazard ratios are reported instead of coefficient values. Standard errors in parentheses. Additional controls include firm-year pair indicators (for all models) and state indicators in columns 3 and $4 .{ }^{*} \mathrm{p}<0.1,{ }^{* *} \mathrm{p}<0.05$, $* * * \mathrm{p}<0.01$. 
Table V: Impact of PHYD insurance on revenues and costs

(1)

Normalized

revenue

\begin{tabular}{lcc}
\hline Entered $^{\text {st }}$ & 0.0354 & $-0.0380^{*}$ \\
$\mathrm{I}\left(\right.$ Entered $\left.1^{\text {st }}\right) \times$ & $(0.0314)$ & $(0.0216)$ \\
$\mathrm{I}(n$ competitors $)$ & & \\
$n=1$ & -0.0112 & 0.0013 \\
& $(0.0228)$ & $(0.0343)$ \\
$n=2$ & 0.0312 & 0.0370 \\
& $(0.0344)$ & $(0.0388)$ \\
$n=3$ or 4 & -0.0442 & 0.0354 \\
& $(0.0370)$ & $(0.0374)$
\end{tabular}

\section{Observations}

(2)

Cost ratio

$-0.0380^{*}$

0.0013

0.0370

(0.0388)

(0.0374)

Notes: The table reports coefficients for a difference-in-differences estimation with state-insurer, state-year, and year-insurer pair fixed effects. The dependent variable in column (1) is log revenue, and the dependent variable in column (2) is the ratio of costs to revenues. A single observation with negative reported revenues was omitted. Robust standard errors (reported in parentheses) are used to account for heteroskedasticity arising from differences in the number insured across observations. ${ }^{*} \mathrm{p}<0.1,{ }^{* *} \mathrm{p}<0.05$ 
Table VI: PHYD insurance and moral hazard

\begin{tabular}{llll}
\hline & \multicolumn{3}{c}{ Log(cars in fatal accidents) } \\
\hline & $(1)$ & $(2)$ & $(3)$ \\
\hline \# firms with PHYD & $-0.0162^{*}$ & & \\
\# firms entering this year & & -0.0125 & -0.0061 \\
& & $(0.0105)$ & $(0.0074)$ \\
\# firms entering last year & & $-0.0210^{*}$ & -0.0116 \\
& & $(0.0111)$ & $(0.0071)$ \\
\# firms entering 2 years ago & & -0.0157 & $-0.0225^{* *}$ \\
& & $(0.0121)$ & $(0.0097)$ \\
\# firms entering 3 years ago & & -0.0067 & -0.0059 \\
& & $(0.0196)$ & $(0.0147)$ \\
\# firms entering 4 years ago & & -0.0098 & -0.0087 \\
& & $(0.0233)$ & $(0.0167)$ \\
Log registered vehicles & $0.122^{* *}$ & $0.123^{* *}$ & 0.0396 \\
& $(0.0608)$ & $(0.0611)$ & $(0.0429)$ \\
\hline Observations & 1071 & 1071 & 55692 \\
\hline
\end{tabular}

Notes: The table reports coefficients for difference-in-differences estimations. In columns 1 and 2, the unit of observations is registry state by year. In column 3, observations are further split by accident location (state). The dependent variable is $\ln$ (autos in fatal accidents $s_{s t}$ ) in columns 1 and 2 . In column 3 , we use $\ln (1+$ autos in fatal accidents $s_{\text {lst }}$ ) as the dependent variable to address observations with zero accidents. In columns 1 and 2, we include registration-state and year fixed effects. In column 3, we include accidentlocation/year pair, and accident-location/registry-state pair fixed effects. In all columns, we additionally include controls for the number of registered vehicles in the vehicle's state of registration. Standard errors, clustered at the state level, are reported in parentheses. ${ }^{*} \mathrm{p}<0.1,{ }^{* *} \mathrm{p}<0.05,{ }^{* * *} \mathrm{p}<0.01$ 


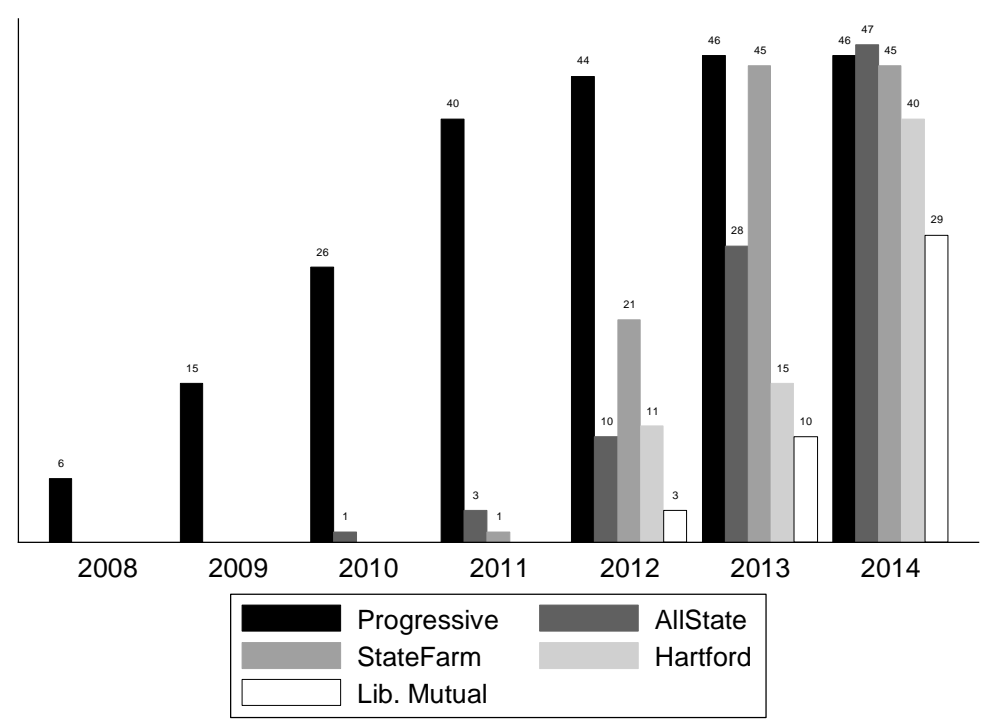

Figure I: PHYD program penetration, by insurance company and time 


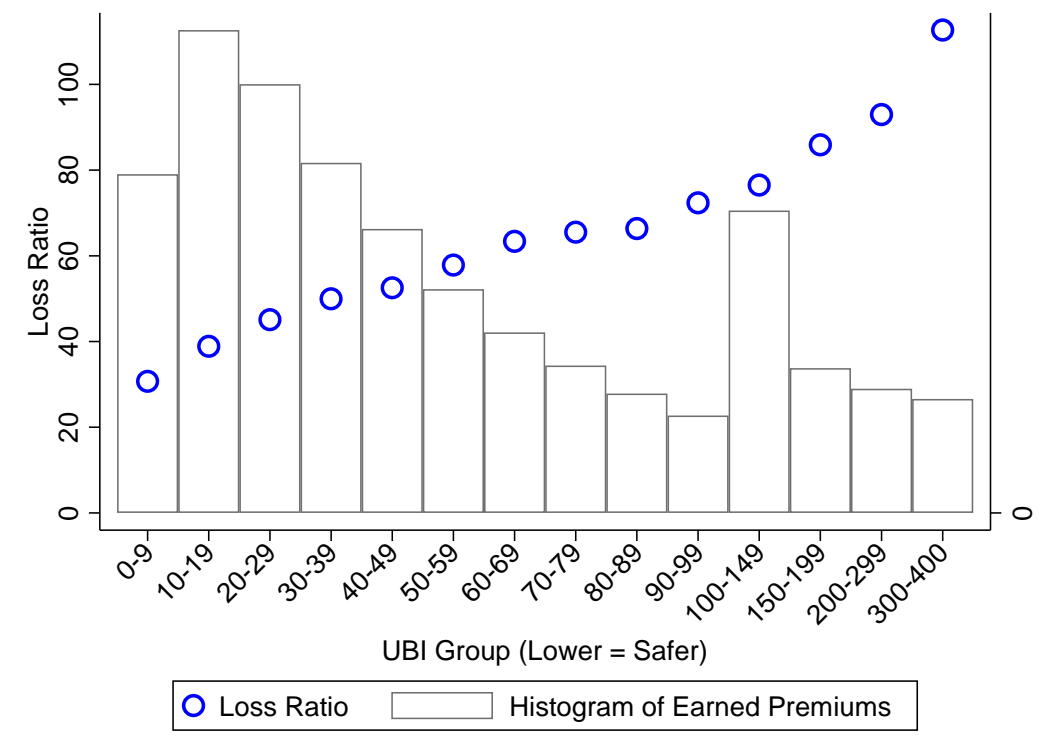

Figure II: Progressive's loss ratio and earned premiums 2014, by PHYD group

Notes: Data correspond to Progressive's SnapShot 2.0 PHYD insurance program nationally. Data are from Progressive's initial PHYD rate filing in Alaska, in 2014. 


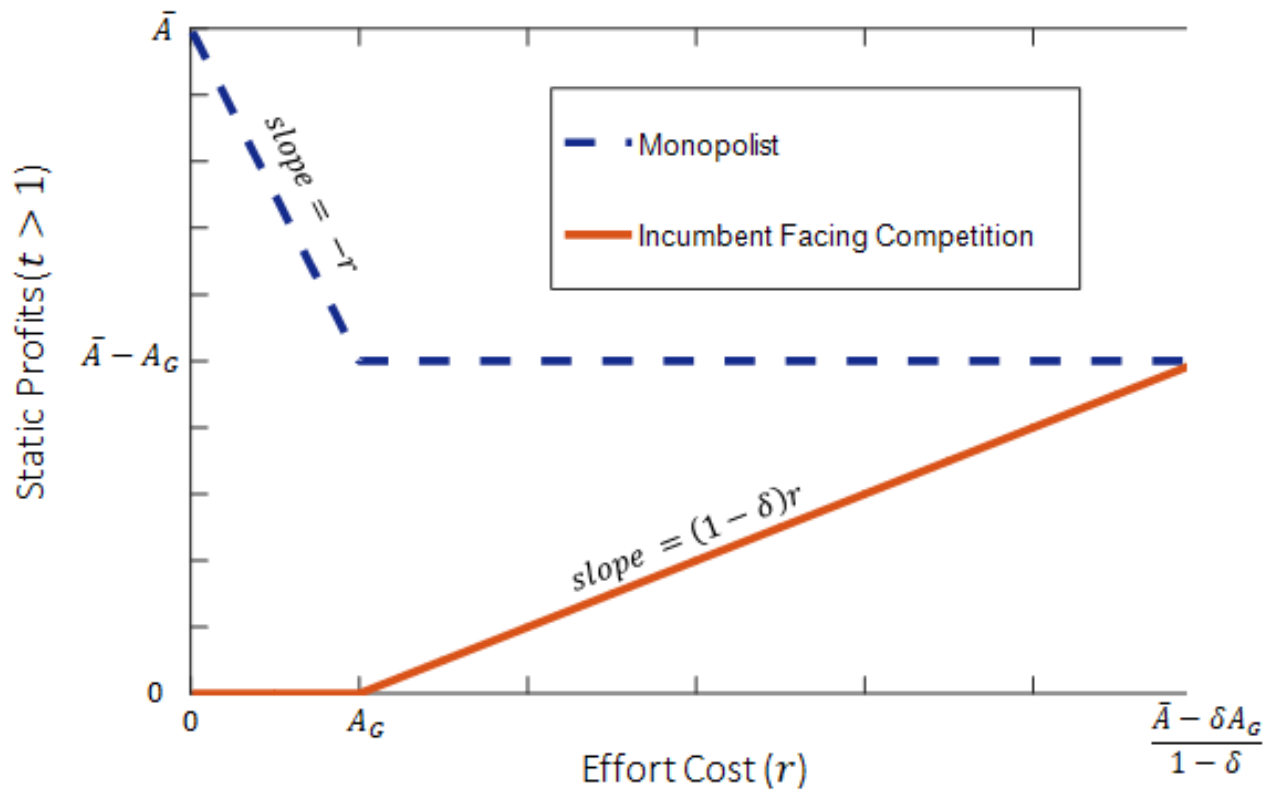

Figure III: Incumbent profits in later periods 


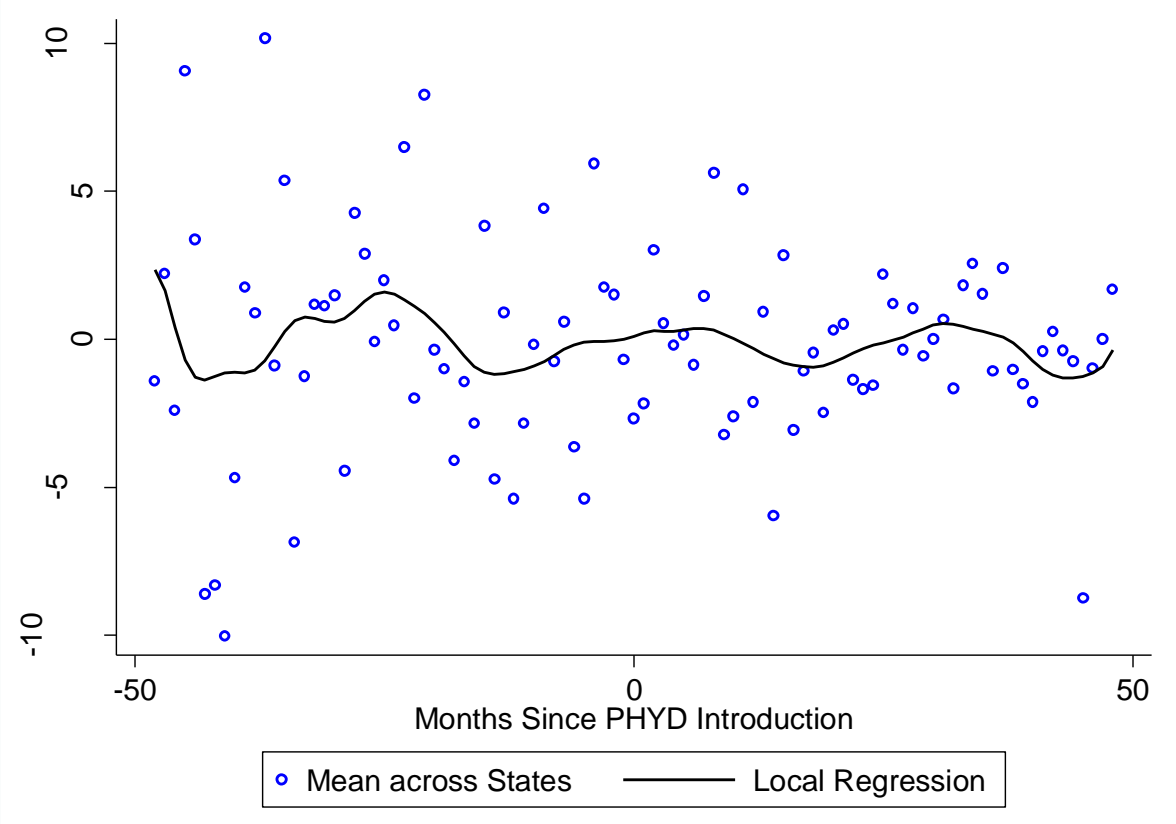

Figure IV: Relative search volume around Progressive Insurance's PHYD introduction 